\title{
Pneumonia ocasionada pela COVID-19 e a importância do diagnóstico como benefício
}

\section{para o tratamento}

\author{
Pneumonia caused by COVIID-19 and the importance of diagnosis as a benefit for treatment \\ Neumonía por COVID-19 y la importancia del diagnóstico como beneficio del tratamiento
}

Paulo Sérgio da Paz Silva Filho ORCID: https://orcid.org/0000-0003-4104-6550 Centro Universitário Maurício de Nassau, Brasil E-mail: pauloosergio1@outlook.com Bruno Leonardo de Sousa Figueiredo ORCID: https://orcid.org/0000-0001-5962-7893 Faculdade Única, Brasil

E-mail: brunofigueiredoenf@gmail.com

Cryshna Letícia Kirchesch

ORCID: https://orcid.org/0000-0002-5866-3216 Universidade Federal de Pelotas, Brasil E-mail: cryshna.clk@gmail.com

Salomão Mendes Amaral ORCID: https://orcid.org/0000-0002-2433-9709

Centro Universitário do Maranhão, Brasil E-mail: amaralcmrj@hotmail.com

Lucas Daniel Lima dos Santos ORCID: https://orcid.org/0000-0002-5317-2805 Universidade Ceuma, Brasil E-mail: lucda.santos@gmail.com

João Pedro Nascimento Ferreira ORCID: https://orcid.org/0000-0001-7676-2720 Universidade Ceuma, Brasil E-mail: jpnascimento_1@outlook.com

Maria Divina dos Santos Borges Farias ORCID: https://orcid.org/0000-0002-1401-808X Centro de Ensino Unificado de Teresina, Brasil

E-mail: mariadivina.bfarias@gmail.com

Woodyson Welson Barros da Silva Batista ORCID: https://orcid.org/0000-0002-8451-9795 Universidade Federal do Piauí, Brasil E-mail: woodywb2020@outlook.com

Mickaelle Bezerra Calaça ORCID: https://orcid.org/0000-0001-9872-6675

Universidade Estadual do Maranhão, Brasil E-mail: mickaellebezerra@outlook.com

Gerardo Vasconcelos Mesquita ORCID: https://orcid.org/0000-00003-4151-7316 Universidade Federal do Piauí, Brasil E-mail: gvmesquita@ufpi.edu.br

Vitor Eulálio Sousa Campelo

ORCID: https://orcid.org/0000-0002-3715-4359 Universidade Federal do Piauí, Brasil E-mail: dr.vcampelo@gmail.com

Hélio Mateus Silva Nascimento ORCID: https://orcid.org/0000-0003-1551-8139 Universidade Federal do Paraná, Brasil E-mail: helio_mateus_@hotmail.com

Amadeu Luis de Carvalho Neto ORCID: https://orcid.org/0000-0001-7726-6120 Universidade Federal do Piauí, Brasil E-mail: amadeusc.neto@ hotmail.com

Gilberto dos Santos Sousa Junior ORCID: https://orcid.org/0000-0002-6023-7451

Universidade Estadual do Maranhão, Brasil E-mail: juniormartins1502@gmail.com 


\author{
Élio Rodrigues da Silva \\ ORCID: https://orcid.org/0000-0001-8254-0921 \\ Universidade Federal do Piaui, Brasil \\ E-mail: eliocirurgia@yahoo.com.br \\ Arquimedes Cavalcante Cardoso \\ ORCID: https://orcid.org/0000-0001-9546-805X \\ Universidade Federal do Piaú, Brasil \\ E-mail: arquimedes@ufpi.edu.br \\ Maria Clara Cronemberger Guimarães Serzedo \\ ORCID: https://orcid.org/0000-0002-6237-4097 \\ Universidade Federal do Piaú, Brasil \\ E-mail: mariaclaraserzedo@gmail.com \\ Carla Patrícia de Carvalho Oliveira \\ ORCID: https://orcid.org/0000-0002-0336-3347 \\ Universidade Federal do Piaú, Brasil \\ E-mail: Carlapatricia@Ufpi.edu.br
}

\begin{abstract}
Resumo
O presente estudo teve como objetivo descrever casos de pneumonia ocasionada pela COVID-19 e a importância do diagnóstico como benefício para o tratamento. Trata-se de um estudo descritivo, do tipo revisão integrativa, de caráter qualitativo. O estudo foi realizado nos meses de janeiro a março de 2021 e constituída a partir da identificação do problema e objetivos, elaboração da pergunta norteadora, busca na literatura, avaliação dos dados, análise e síntese de dados e discussão e apresentação dos resultados. As questões da pesquisa foram: "Qual a relação da pneumonia com a COVID-19?", "Qual a importância do diagnóstico rápido da COVID-19?" e "Qual o tratamento empregado em pacientes com pneumonia ocasionada pela COVID-19?". Os critérios de inclusão foram: artigos disponibilizados na íntegra, disponíveis nos idiomas português, espanhol e inglês e publicados entre os anos de 2019 e 2021 . Os critérios de exclusão foram: artigos incompletos, cartas ao editor, debates, resenhas, resumos ou artigos publicados em anais de eventos, indisponíveis na íntegra e duplicados. Foram considerados, inicialmente, 346 estudos com a temática proposta; dentre estes, foram excluídos 120 estudos, de acordo com os critérios de exclusão estabelecidos. Após a aplicação dos critérios de inclusão, restaram 12 estudos. O diagnóstico da pneumonia por COVID-19 é possível através de PCR-TR positivo ou presença de alta suspeição clínica (clínica compatível + epidemiologia favorável) associada à tomografia computadorizada com padrão em vidro fosco periférico bilateral de lobos inferiores.
\end{abstract}

Palavras-chave: Pneumonia; COVID-19; Tratamento; Diagnóstico.

\begin{abstract}
The present study aimed to describe cases of pneumonia caused by COVID-19 and the importance of diagnosis as a benefit for treatment. This is a descriptive, integrative review, qualitative study. The study was carried out from January to March 2021 and consisted of identifying the problem and objectives, elaborating the guiding question, searching the literature, evaluating the data, analyzing and synthesizing the data and discussing and presenting the results. The research questions were: "What is the relationship between pneumonia and COVID-19?", "What is the importance of the rapid diagnosis of COVID-19?" And "What is the treatment used in patients with pneumonia caused by COVID-19?". The inclusion criteria were: articles made available in full, available in Portuguese, Spanish and English and published between the years 2019 and 2021. The exclusion criteria were: incomplete articles, letters to the editor, debates, reviews, abstracts or published articles in annals of events, unavailable in full and duplicated. Initially, 346 studies with the proposed theme were considered; among these, 120 studies were excluded, according to the established exclusion criteria. After applying the inclusion criteria, 12 studies remained. The diagnosis of pneumonia due to covid-19 is possible through positive CRP-TR or the presence of high clinical suspicion (compatible clinic + favorable epidemiology) associated with CT with a bilateral peripheral ground-glass pattern of lower lobes. Epidemiological measures for infection control management should be carried out.
\end{abstract}

Keywords: Pneumonia; COVID-19; Treatment; Diagnosis.

\title{
Resumen
}

El presente estudio tuvo como objetivo describir los casos de neumonía por COVID-19 y la importancia del diagnóstico como beneficio del tratamiento. Se trata de un estudio cualitativo, descriptivo, de revisión integradora. El estudio se realizó de enero a marzo de 2021 y se constituyó a partir de la identificación del problema y objetivos, elaboración de la pregunta orientadora, búsqueda en la literatura, evaluación de datos, análisis y síntesis de datos y discusión y presentación de los resultados. Las preguntas de investigación fueron: "¿Cuál es la relación entre neumonía y COVID19?", "¿Qué importancia tiene el diagnóstico rápido de COVID-19?" Y "¿Qué tratamiento se utiliza en pacientes con neumonía causada por COVID-19?". Los criterios de inclusión fueron: artículos disponibles en su totalidad, disponibles en portugués, español e inglés y publicados entre los años 2019 y 2021. Los criterios de exclusión fueron: artículos incompletos, cartas al editor, debates, revisiones, resúmenes o artículos publicados en anales. de eventos, no disponible 
en su totalidad y duplicado. Inicialmente, se consideraron 346 estudios con el tema propuesto; entre estos, se excluyeron 120 estudios, de acuerdo con los criterios de exclusión establecidos. Después de aplicar los criterios de inclusión, quedaron 12 estudios. El diagnóstico de neumonía por covid-19 es posible a través de PCR-TR positiva o la presencia de alta sospecha clínica (clínica compatible + epidemiología favorable) asociada a TC con patrón de vidrio esmerilado periférico bilateral de lóbulos inferiores. Se deben tomar medidas epidemiológicas para el manejo del control de infecciones.

Palabras clave: Neumonía; COVID-19; Tratamiento; Diagnóstico.

\section{Introdução}

A infecção por coronavírus (COVID-19) é ocasionada por $S A R S-C o V-2$ onde é conhecido por ser o agente responsável de uma doença potencialmente fatal que é uma grande preocupação global de saúde pública. Esta doença foi primeiramente identificada em Wuhan, província de Hubei, na China que posteriormente se espalhou pelo mundo, atingindo mais de 120 países (Ribeiro \& Silva, 2021).

As vias de transmissão do coronavírus podem ser classificadas como: direta, que ocorrer a partir de tosse, espirro e perdigotos e a transmissão por contato com mucosa oral, nasal e dos olhos. Em alguns relatos, ocorreu a análise das mucosas em casos suspeitos e confirmados, sugerindo uma transmissão não limitada ao trato respiratório. Pode-se verificar também que o vírus pode ser transmitido de pessoa para pessoa por meio de contato direto ou indireto, como fluidos e saliva. Além disso, na Alemanha, foi relatado casos de transmissão por meio do contato com paciente assintomático (Costa et al., 2020).

A COVID-19 tem se destacado por ser uma doença infectocontagiosa emergente, a adoção das medidas de prevenção da COVID-19 são a melhor opção para o controle da propagação do vírus. Com isso, várias medidas foram tomadas com a finalidade de controlar a transmissão do SARS-CoV-2, fronteiras foram fechadas e diversas recomendações foram estabelecidas, como o isolamento social, orientações a frequente lavagem das mãos, à limpeza e desinfecção de superfícies com mais rigor e o uso obrigatório de máscaras em ambientes públicos (Soares et al., 2021).

Mo et al. (2020), descreveram que pacientes no geral apresentaram baixa eficácia ao tratamento após a hospitalização e porem desenvolver pneumonia grave, edema pulmonar, síndrome do desconforto respiratório agudo (SDRA) ou falência de múltiplos órgãos. No momento, as informações sobre as características clínicas do covid-19 tornam-se indispensaveis para o acompanhamento do paciente acometido pela doença.

A pneumonia é uma doença comum onde é ocasionada por diferentes tipos de microrganismos, como bactérias, vírus e fungos. A palavra "Pneumonia" tem origem da palavra grega "Pneumon" que se traduz em pulmões. Assim, a palavra pneumonia está diretamente ligada a doenças pulmonares. Em outras palavras, a pneumonia é uma doença onde ocorre a inflamação de um ou de ambos os parênquimas pulmonares. Com base na infecção, a pneumonia ocorre como resultado da inflamação causada por patógenos que levam os alvéolos do pulmão a se encherem de líquido ou pus, levando à diminuição de dióxido de carbono (CO 2) e oxigênio $(\mathrm{O} 2)$ troca entre o sangue e os pulmões, dificultando a respiração das pessoas infectadas. Alguns dos sintomas de pneumonia incluem falta de ar, febre, tosse, dor no peito, entre outros sintomas (Ibrahim et al., 2021).

Sabe-se que os coronavírus invadem os alvéolos pulmonares (órgão responsável pela troca de O 2 e CO 2), causando pneumonia. A partir disso o presente estudo teve como objetivo descrever estudos sobre pneumonia ocasionada pela COVID-19 e a importância do diagnóstico como benefício para o tratamento.

\section{Metodologia}

\subsection{Natureza do estudo}

Trata-se de um estudo descritivo, do tipo revisão integrativa, de caráter qualitativo uma vez que as pesquisa qualitativas têm como matéria prima um conjunto de substantivos cujos sentidos se complementam: "experiência, vivência, senso comum e ação. E o movimento que informa qualquer abordagem, se baseia em quatro verbos: escutar, compreender, interpretar e 
dialetizar". A revisão de literatura permite-nos aprofundar, dentro diversos autores e referenciais, sobre os discursos e principais temas abordados, fazendo um compilado arrojado que nos permite olhar por diversos olhares um mesmo objeto de pesquisa (Gil, 2017; Pereira et al., 2018).

O estudo foi realizado nos meses de janeiro a março de 2021 e constituída a partir da identificação do problema e objetivos, elaboração da pergunta norteadora, busca na literatura, avaliação dos dados, análise e síntese de dados e discussão e apresentação dos resultados.

Para estruturar essa revisão seguiram-se 5 etapas metodológicas: identificação do tema e questão de pesquisa; estabelecimento de critérios para inclusão e exclusão de estudos; definição das informações a serem extraídas dos estudos selecionados; avaliação dos estudos incluídos na revisão integrativa; Interpretação dos resultados; apresentação da revisão ou síntese do conhecimento.

\subsection{Questões norteadoras}

As questões da pesquisa foram: "Qual a relação da pneumonia com a COVID-19?", "Qual a importância do diagnóstico rápido da COVID-19?" e "Qual o tratamento empregado em pacientes com pneumonia ocasionada pela COVID-19?".

\subsection{Estratégia de busca}

Para a realização desse estudo, foram consultadas as bases de dados: Medical Literature Analysis and Retrieval System Online (MEDLINE), Scholar Google e Scientific Eletronic Library Online (SCIELO). Utilizou-se os Descritores em Ciências da Saúde (DeCS) de forma associada: "Pneumonia", "Covid-19", "tratamento" e " diagnóstico".

\subsection{Critérios de inclusão}

Os critérios de inclusão foram: artigos disponibilizados na íntegra, disponíveis nos idiomas português, espanhol e inglês e publicados entre os anos de 2019 e 2021.

\subsection{Critérios de exclusão}

Os critérios de exclusão foram: artigos incompletos, cartas ao editor, debates, resenhas, resumos ou artigos publicados em anais de eventos, indisponíveis na íntegra e duplicados.

\subsection{Análise e interpretação dos dados}

A análise e a interpretação dos dados foram feitas por meio da descrição dos achados. Os dados foram organizados em uma tabela Excel®, que compreendeu as seguintes colunas de sintetização: título do estudo, base de dados, periódico, ano de publicação, contexto/local de estudo, desenho metodológico, resultados e conclusões.

\subsection{Aspectos éticos}

Cabe salientar que os aspectos éticos e os direitos de autoria foram devidamente respeitados, por meio da referenciação dos autores dos trabalhos utilizados. Por se tratar de um estudo de revisão de literatura, não houve necessidade de apreciação por um Comitê de Ética em Pesquisa (CEP). 


\section{Resultados e Discussão}

Foram considerados, inicialmente, 346 estudos com a temática proposta; dentre estes, foram excluídos 120 estudos, de acordo com os critérios de exclusão estabelecidos. Após a aplicação dos critérios de inclusão, restaram 12 estudos.

Considerando, inicialmente, a busca dos artigos que abordassem a temática proposta e para compor a fundamentação da discussão deste estudo, foram recuperados pelas estratégias de busca um total de 12 artigos que foram analisados e discutidos integralmente.

\section{Quadro 1.}

\begin{tabular}{|c|c|c|c|}
\hline NOME DO ARTIGO & AUTOR/ANO & OBJETIVOS & CONCLUSÃO \\
\hline $\begin{array}{l}\text { O papel da imagem na } \\
\text { nova pneumonia por } \\
\text { coronavírus em } 2019 \\
\text { (COVID-19). }\end{array}$ & $\begin{array}{l}\text { (Yang et al., } \\
\text { 2020). }\end{array}$ & $\begin{array}{c}\text { Apresentar brevemente a nova } \\
\text { pneumonia por coronavírus e destacar o } \\
\text { valor dos exames de imagem em seu } \\
\text { diagnóstico. }\end{array}$ & $\begin{array}{l}\text { Na situação atual, a imagem de COVID-19, } \\
\text { particularmente com TC de tórax, tem um valor } \\
\text { muito alto porque mostra manifestações } \\
\text { características e permitiu que os médicos da linha de } \\
\text { frente tivessem o diagnóstico primário em seu } \\
\text { primeiro contato com pacientes suspeitos, mesmo } \\
\text { na presença de inicialmente falsos resultados } \\
\text { laboratoriais negativos. }\end{array}$ \\
\hline $\begin{array}{l}\text { COVID-19: uma breve } \\
\text { atualização para } \\
\text { radiologistas }\end{array}$ & $\begin{array}{l}\text { (Meirelles, } \\
\text { 2020). }\end{array}$ & $\begin{array}{l}\text { Abordar os principais aspectos clínicos e } \\
\text { imaginológicos da COVID-19, diretrizes } \\
\text { para solicitação de exames de imagem, } \\
\text { recomendações para proteção dos } \\
\text { pacientes e profissionais de saúde, } \\
\text { quantificação dos achados de imagem, } \\
\text { modelos de relatório estruturado e } \\
\text { descrição de algumas inovações que têm } \\
\text { surgido no momento da pandemia }\end{array}$ & $\begin{array}{l}\text { A pandemia pelo novo coronavírus tem modificado } \\
\text { de forma impactante a rotina dos seres humanos e o } \\
\text { setor de saúde. É fundamental que médicos } \\
\text { radiologistas estejam a par dos principais aspectos } \\
\text { clínicos e imaginológicos da COVID-19, assim } \\
\text { como as diretrizes para solicitação e utilização dos } \\
\text { métodos de imagem, medidas de proteção a } \\
\text { pacientes e profissionais de saúde. }\end{array}$ \\
\hline $\begin{array}{l}\text { Pneumonia COVID-19: } \\
\text { SDRA ou não? }\end{array}$ & $\begin{array}{l}\text { (Gattinoni; } \\
\text { Chiumello \& } \\
\text { Rossi, 2020). }\end{array}$ & $\begin{array}{l}\text { Descrever se a Pneumonia COVID-19 é } \\
\text { uma Síndrome do desconforto } \\
\text { respiratório agudo. }\end{array}$ & $\begin{array}{l}\text { Com base na observação detalhada de vários casos e } \\
\text { discussões com colegas que tratam de pacientes com } \\
\text { COVID-19, os autores hipotetizaram que os } \\
\text { diferentes padrões de COVID-19 encontrados na } \\
\text { admissão no departamento de emergência dependem } \\
\text { da interação entre três fatores: (1) a gravidade da } \\
\text { infecção, a resposta do hospedeiro, reserva } \\
\text { fisiológica e comorbidades; (2) a capacidade de } \\
\text { resposta ventilatória do paciente à hipoxemia; (3) o } \\
\text { tempo decorrido entre o início da doença e a } \\
\text { observação no hospital. }\end{array}$ \\
\hline $\begin{array}{l}\text { Prevalence of venous } \\
\text { thromboembolism in } \\
\text { patients with severe } \\
\text { novel coronavirus } \\
\text { pneumonia. }\end{array}$ & $\begin{array}{l}\text { (Cui et al., } \\
\text { 2020). }\end{array}$ & $\begin{array}{l}\text { Determinar a incidência de TEV em } \\
\text { pacientes com PCN grave. }\end{array}$ & $\begin{array}{l}\text { A incidência de TEV em pacientes com PCN grave } \\
\text { é de } 25 \% \text { (20/81), o que pode estar relacionado a } \\
\text { mau prognóstico. O aumento significativo do } \\
\text { dímero D em pacientes com NCP grave é um bom } \\
\text { índice para identificar grupos de alto risco de TEV. }\end{array}$ \\
\hline $\begin{array}{l}\text { Achados de } \\
\text { ultrassonografia } \\
\text { pulmonar de uma nova } \\
\text { pneumonia por vírus } \\
\text { corona durante a } \\
\text { epidemia de 2019-2020 }\end{array}$ & $\begin{array}{l}\text { (Peng et al., } \\
\text { 2020). }\end{array}$ & $\begin{array}{c}\text { Relatar achados de ultrassonografia } \\
\text { pulmonar de uma nova pneumonia por } \\
\text { vírus corona durante a epidemia de 2019- } \\
2020\end{array}$ & $\begin{array}{l}\text { Ultrassonografia pulmonar tem grande utilidade } \\
\text { para o tratamento de COVID-19 com envolvimento } \\
\text { respiratório devido à sua segurança, repetibilidade, } \\
\text { ausência de radiação, baixo custo e uso no local de } \\
\text { atendimento; A TC de tórax pode ser reservada para } \\
\text { os casos em que a ultrassonografia pulmonar não é } \\
\text { suficiente para responder à questão clínica. }\end{array}$ \\
\hline $\begin{array}{l}\text { Pneumonia por COVID- } \\
\text { 19: qual o papel da } \\
\text { imagem no diagnóstico? }\end{array}$ & $\begin{array}{l}\text { (Araujo-Filho } \\
\text { et al., 2020). }\end{array}$ & $\begin{array}{c}\text { Buscou informar o papel da imagem no } \\
\text { diagnóstico da Pneumonia por COVID- } \\
19 .\end{array}$ & $\begin{array}{l}\text { A TC não deve ser usada na triagem de COVID-19 } \\
\text { em pacientes assintomáticos, devendo ser } \\
\text { considerada em pacientes hospitalizados, } \\
\text { sintomáticos ou em situações clínicas específicas. }\end{array}$ \\
\hline $\begin{array}{l}\text { TC de tórax para } \\
\text { pneumonia com doença } \\
\text { coronavírus típica } 2019 \\
\text { (COVID-19): relação }\end{array}$ & $\begin{array}{l}\text { (Xie et al., } \\
\text { 2020). }\end{array}$ & $\begin{array}{l}\text { Descrever a importância do TC de tórax } \\
\text { para pneumonia com doença coronavírus } \\
\text { típica } 2019 \text { (COVID-19): relação com } \\
\text { teste de RT-PCR negativo. }\end{array}$ & $\begin{array}{l}\text { Os autores apresentam os achados da TC de tórax de } \\
\text { cinco pacientes com infecção por COVID-19 que } \\
\text { tiveram resultados iniciais de RT-PCR } \\
\text { negativos. Todos os cinco pacientes tiveram }\end{array}$ \\
\hline
\end{tabular}




\begin{tabular}{|c|c|c|c|}
\hline $\begin{array}{c}\text { com teste de RT-PCR } \\
\text { negativo. }\end{array}$ & & & $\begin{array}{c}\text { achados de imagem típicos, incluindo opacidade em } \\
\text { vidro fosco (cinco pacientes) e / ou opacidade em } \\
\text { vidro fosco mista e consolidação mista (dois } \\
\text { pacientes). }\end{array}$ \\
\hline $\begin{array}{l}\text { RT-PCR em tempo real } \\
\text { na detecção de COVID- } \\
\text { 19: problemas que afetam } \\
\text { os resultados. }\end{array}$ & $\begin{array}{l}\text { (Tahamtan; } \\
\text { Ardebili, } \\
\text { 2020). }\end{array}$ & $\begin{array}{l}\text { Informar os problemas que afetam os } \\
\text { resultados da RT-PCR em tempo real na } \\
\text { detecção de COVID-19 }\end{array}$ & $\begin{array}{l}\text { Os resultados dos testes de RT-PCR em tempo real } \\
\text { devem ser interpretados com cautela. No caso de } \\
\text { resultado negativo de RT-PCR em tempo real com } \\
\text { suspeita de características clínicas para COVID-19, } \\
\text { especialmente quando apenas amostras do trato } \\
\text { respiratório superior foram testadas, vários tipos de } \\
\text { amostra em diferentes momentos, incluindo do trato } \\
\text { respiratório inferior, se possível, devem ser testado. }\end{array}$ \\
\hline $\begin{array}{l}\text { Tratamento precoce para } \\
\text { COVID-19 baseado em } \\
\text { evidência científica }\end{array}$ & $\begin{array}{l}\text { (Vieira et al., } \\
\text { 2020). }\end{array}$ & $\begin{array}{l}\text { Avaliar o papel da hidroxicloroquina e da } \\
\text { cloroquina no tratamento da Fase I da } \\
\text { COVID-19 com o objetivo de apresentar } \\
\text { uma proposta de tratamento precoce em } \\
\text { Unidades Básicas de Saúde (UBS). }\end{array}$ & $\begin{array}{c}\text { Não existe evidência nível 1A de que a associação } \\
\text { de cloroquina ou hidroxicloroquina e azitromicina } \\
\text { seja efetiva no tratamento da COVID-19. }\end{array}$ \\
\hline $\begin{array}{l}\text { Farmacoeconomia } \\
\text { aplicada ao tratamento } \\
\text { medicamentoso para a } \\
\text { COVID-19 em um } \\
\text { hospital campanha. }\end{array}$ & $\begin{array}{l}\text { (Braúna et al., } \\
\text { 2021). }\end{array}$ & $\begin{array}{l}\text { Sintetizar a terapia e os custos diretos } \\
\text { envolvidos no tratamento farmacológico } \\
\text { da COVID-19 observadosemumhospital } \\
\text { campanha do estado do Piauí -Brasil. }\end{array}$ & $\begin{array}{l}\text { Uma estratégia promissorapara tratamento da } \\
\text { COVID-19 pareceu ser o uso de medicamentos que } \\
\text { não possuem eficácia comprovada visto quealguns } \\
\text { estudos analisados apontaram para o uso destes } \\
\text { como possível terapia farmacológica contra a } \\
\text { infecção. }\end{array}$ \\
\hline $\begin{array}{l}\text { Terapias } \\
\text { imunossupressoras no } \\
\text { tratamento de COVID- } \\
\text { 19: uma revisão } \\
\text { integrativa da literatura. }\end{array}$ & $\begin{array}{l}\text { (Machado et } \\
\text { al., 2021). }\end{array}$ & $\begin{array}{c}\text { Descrever as possibilidades de } \\
\text { tratamento para a doença Covid- } 19 \text { com } \\
\text { base em drogas que apresentem efeito } \\
\text { imunossupressor. }\end{array}$ & $\begin{array}{l}\text { Os estudos clínicos que analisaram o tratamento } \\
\text { com corticosteroides, os de terapias alternativas } \\
\text { utilizando exossomos e hemoperfusão, os com a } \\
\text { droga Tocilizumabe e os com hidroxicloroquina e } \\
\text { azitromicina mostraram que, de forma geral, os } \\
\text { níveis de saturação de oxigênio no sangue } \\
\text { melhoraram significativamente e houve } \\
\text { dispensabilidade de ventilação mecânica, sendo que } \\
\text { esses prognósticos foram encontrados } \\
\text { concomitantemente a diminuição de marcadores } \\
\text { inflamatórios, como a IL-6. }\end{array}$ \\
\hline $\begin{array}{l}\text { Esquemas terapêuticos } \\
\text { para combate da Covid- } \\
\text { 19: revisão sistemática }\end{array}$ & $\begin{array}{l}\text { Zuil et al. } \\
\text { (2021). }\end{array}$ & $\begin{array}{l}\text { Investigar os principais esquemas } \\
\text { terapêuticos utilizados até o momento no } \\
\text { combate à Covid19 no cenário mundial. }\end{array}$ & $\begin{array}{l}\text { A terapia mais estudada entre os artigos foi a } \\
\text { associação lopinavir/ritonavir, utilizada em sete } \\
\text { artigos diferentes, seguida do arbidol (quatro } \\
\text { artigos), medicina tradicional Chinesa (dois artigos) } \\
\text { e hidroxicloroquina + azitromicina (dois artigos). }\end{array}$ \\
\hline
\end{tabular}

Fonte: Autores (2021).

As informações a serem discutidas foram categorizadas para uma melhor análise, interpretação e esclarecimento das temáticas abordadas. Optou-se por dividir em 3 tópicos (categorias), buscando uma melhor associação entre os resultados encontrados na literatura.

\section{- Pneumonia e Covid-19}

Em dezembro de 2019, a cidade de Wuhan, localizada na província de Hubei, na China, tornou-se o epicentro de um surto de pneumonia. Essa pneumonia foi confirmada como secundária à infecção por um novo coronavírus. Onde esse vírus recebeu o nome de novo coronavírus 2019 (2019-nCoV), mas em 11 de fevereiro de 2020, a doença foi denominada COVID-19 pela Organização Mundial da Saúde (OMS), e o vírus foi denominado síndrome respiratória aguda grave coronavírus 2 (SARSCoV-2) pelo Comitê Internacional de Taxonomia de Vírus (Yang et al., 2020).

A apresentação clínica da COVID-19 pode ser inespecífica, com sintomas comuns a outras síndromes gripais. Maior parte dos casos de COVID-19 apresenta sintomas leves, sem evidência de pneumonia viral e hipoxia; cerca de $15 \%$ dos pacientes podem evoluir para formas moderadas, com sinais clínicos de pneumonia (febre, tosse, dispneia, taquipneia), porém não 
apresentam sinais de pneumonia grave, além disso, observa-se uma saturação de O2 no sangue periférico > 90\% em ar ambiente; e 5\% dos pacientes apresentam formas graves da doença, com sinais clínicos de pneumonia (febre, tosse, dispneia, taquipneia), além de pelo menos um dos seguintes achados: saturação de O2 no sangue periférico $<90 \%$ em ar ambiente, frequência respiratória > 30 respirações/minuto ou distúrbio respiratório grave (Meirelles, 2020).

A pneumonia COVID-19 é uma doença específica com fenótipos peculiares. A característica mais evidente é a dissociação entre a gravidade da hipoxemia e a manutenção de uma mecânica respiratória relativamente boa. A complacência mediana do sistema respiratório é geralmente em torno de $50 \mathrm{ml} / \mathrm{cmH}_{2} \mathrm{O}$. É relevante informar que os pacientes com complacência respiratória menor ou maior do que o valor mediano apresentam hipoxemia de gravidade semelhante (Gattinoni; Chiumello \& Rossi, 2020).

Cui et al. (2020), relataram que pode-se observar quadro de coagulação em pacientes com pneumonia por coronavírus grave, onde está claramente correlacionada com mau prognóstico. Os parâmetros convencionais de coagulação de pacientes em unidade de terapia intensiva (UTI) foram significativamente maiores do que os de pacientes não internados em UTI. No entanto, a prevalência de tromboembolismo venoso em pacientes de UTI com pneumonia por coronavírus grave é desconhecida. Portanto, o objetivo deste estudo foi explorar a incidência de tromboembolismo venoso em tais pacientes e investigar as diferenças entre pacientes com tromboembolismo venoso e não tromboembolismo venoso.

\section{- Diagnóstico}

Como as doenças relacionada ao pulmão em muitos casos se desenvolvem antes do aparecimento de sinais clínicos e da detecção de ácido nucleico, pesquisadores recomendam a tomografia computadorizada (TC) de tórax precoce para a triagem de pacientes suspeitos. A alta taxa de transmissão do SARS-CoV-2 e o risco de transportar pacientes instáveis com hipoxemia e insuficiência hemodinâmica tornam a TC de tórax uma opção limitada para o paciente com COVID-19 suspeito ou estabelecido. A ultrassonografia pulmonar dispõem de resultados similares aos da TC de tórax e com uma melhor qualidade em comparação à radiografia de tórax padrão para avaliação de pneumonia e/ou síndrome do desconforto respiratório do adulto (SDRA) com a vantagem adicional de facilidade de uso no local de atendimento, repetibilidade, ausência de exposição à radiação e baixo custo (Peng et al., 2020).

Os achados tomográficos da pneumonia por COVID-19 são inespecíficos, com sinais parecido aos de outras infecções pulmonares, além disso podem variar de acordo com a fase em que a doença se encontra, é sempre importante que seja realizado uma correlação com evidências clínicas e laboratoriais da infecção por COVID-19. Porém, a radiografia de tórax pode ter alguma utilidade, onde apresenta um potencial que venha a servir como uma ferramenta de triagem na linha de frente em ambientes médicos com recursos limitados ou em casos em que a condição física do paciente não permite o transporte para o tomógrafo do departamento de radiologia. Até o presente momento, recomenda-se que o diagnóstico final da covid-19 seja realizado a partir da confirmação por meio do teste positivo de RT-PCR ou sequenciamento genético (Araujo-Filho et al., 2020).

No estudo realizado por Yang et al. (2020), descreveram uma pesquisa que realizou um estudo de coorte, onde os achados da TC de tórax mostraram uma distribuição bilateral de opacidade em vidro fosco e consolidação em 138 pacientes. A radiografia de tórax em um homem de 61 anos mostra opacidades irregulares bilaterais, um pouco nodulares, na parte média e inferior dos pulmões. Imagens de tomografia computadorizada (TC) sem contraste ( b ). Nas imagens pode-se observar várias opacidades em vidro fosco na periferia dos pulmões bilaterais, sendo que esses padrões são achados de TC comuns e característicos da nova pneumonia por covid-19. A imagem da TC de tórax de um homem ( c ) mostra consolidação no lobo superior direito periférico e uma área irregular de opacidade em vidro fosco com algum espessamento do septo interlobular intra e interlobular associado dentro do lobo superior esquerdo. 
Figura 1. A radiografia de tórax e a TC de tórax típicas de COVID-19.

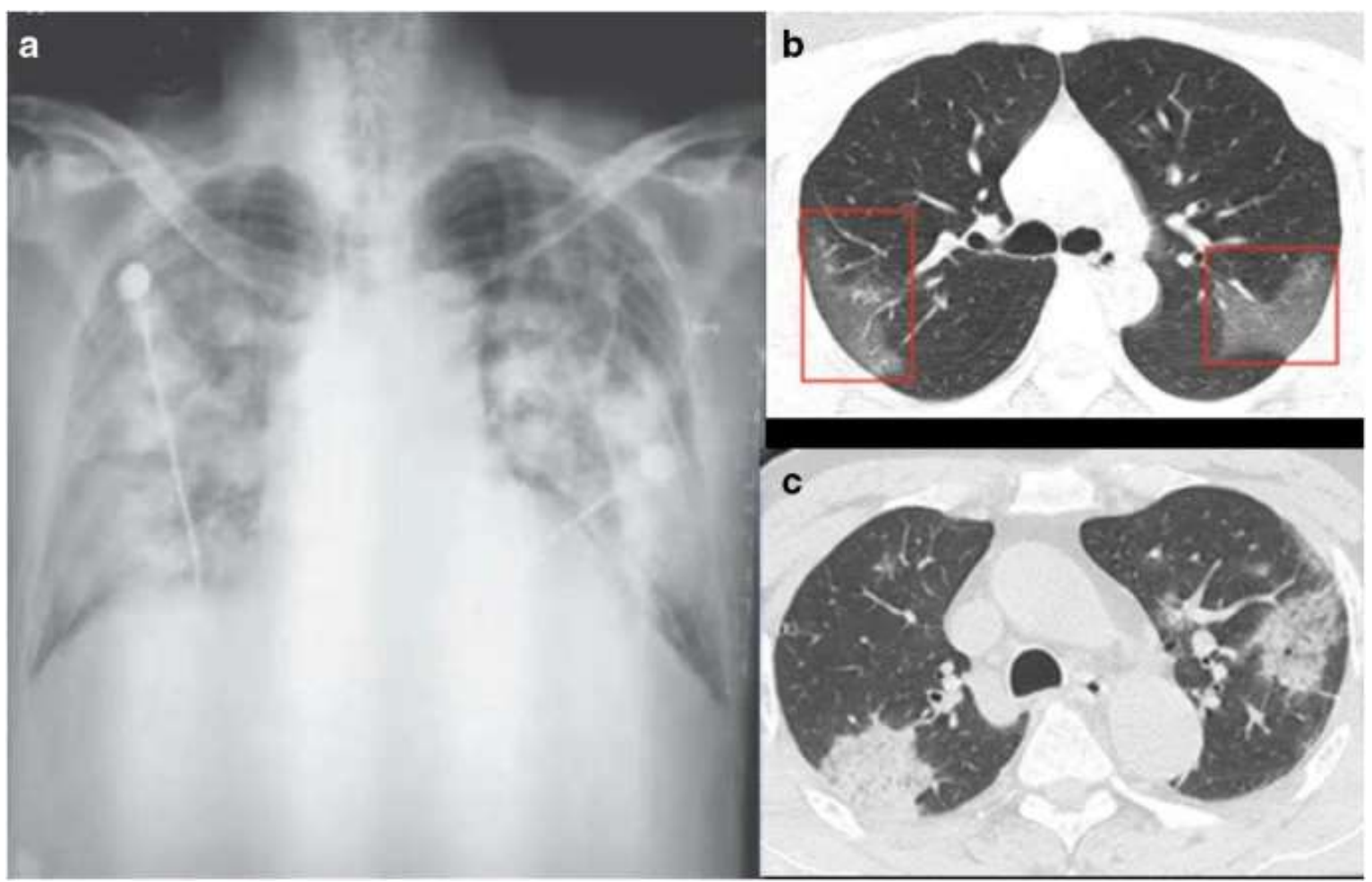

Fonte: Adaptada de Yang et al. (2020).

Segundo Meirelles (2020), o padrão típico para pneumonia viral é a presença de vidro fosco bilateral periférico ou multifocal de forma, além da presença do sinal do halo invertido ou outros sinais de pneumonia em organização. No mesmo estudo foi relado que a Sociedade Fleischner, composta por médicos radiologistas, pneumologistas, patologistas e cirurgiões de diversos países, também não recomenda a TC de tórax para pacientes assintomáticos ou com sintomas leves, somente quando tem a suspeita de progressão da doença. A Fleischner recomenda-se que a TC de tórax deve ser realizado em pacientes moderados ou graves, para aqueles com piora do estado respiratório e para pacientes curados da doença caso apresentem posteriormente hipoxemia ou perda funcional

Xie et al. (2020), descreveram um estudo onde alguns pacientes com achados de TC de tórax positivos apresentaram resultados negativos de testes de reação em cadeia da polimerase de transcrição reversa em tempo real (RT-PCR) para Covid-19. Os autores relataram achados da TC de tórax de cinco pacientes com infecção por COVID-19, onde tiveram resultados iniciais de RT-PCR negativos. Em todos os pacientes pode-se observar imagem típicas, juntamente com opacidade em vidro fosco (cinco pacientes) e / ou opacidade em vidro fosco mista e consolidação mista (dois pacientes). Posteriormente foi isolamento para presumível pneumonia por COVID-19, a partir isso verificou-se que todos os pacientes foram eventualmente confirmados para infecção por COVID-19 por meio de testes repetidos de esfregaço.

As abordagens fundamentadas nos achados de ácido nucleico se tornaram uma tecnologia rápida e confiável para detecção viral. Entre os testes de ácido nucleico, o método de PCR que vem sendo considerado o "padrão ouro" para a detecção de alguns vírus e é caracterizado pela detecção rápida, alta sensibilidade e especificidade. Diante isso, a transcriptase reversa em tempo real-PCR (RTPCR) atua com uma grande importância na detecção do SARS-CoV-2 por conta de seus benefícios como um ensaio qualitativo simples e específico. Sabe-se também que o RT-PCR em tempo real tem sensibilidade suficiente para ajudar no diagnóstico de infecção precoce (Tahamtan; Ardebili, 2020).

Observou-se que países que realizaram testagem massiva da população, a exemplo da Coreia do Sul, Singapura e 
Alemanha, obtiveram resultados satisfatório a respeito da diminuir de óbitos relacionados ao COVID-19. Porém, os testes de RTPCR têm protocolos de alta complexidade e custo, além disso, sua realização dá-se por meio de laboratórios centrais, pois requerem equipes treinadas e equipamentos de elevado custo. Normalmente o teste RT-PCR demora cerca de 4 a 6 horas, porém pode ser necessário mais de 24 horas entre a recepção da amostra e a emissão do resultado (Vieira et al., 2020).

\section{- Tratamento}

Pacientes com infecção leve por Covid-19 podem ser tratados em domicílio, buscando assim, prevenir a transmissão para outros indivíduos. Para os casos com sintomas leves, o procedimento adotado é o isolamento domiciliar, o uso de máscara facial na presença de outra pessoa em qualquer ambiente (sala, quarto, carro, entre outros) e a desinfecção de todas as superfícies de contato (Vieira et al., 2020).

Segundo Braúna et al. (2021), os medicamentos indicados para protocolo clínico do hospital de campanha para terapia farmacológica de covid-19 nas fases inicial e pulmonar mais utilizados foram: heparina, omeprazol, hidroxicloroquina, ceftriaxona, azitromicina, oseltamivir, ivermectina, metilprednisolona, juntamente com os medicamentos em caso de necessidade dipirona, metoclopramida, glicose e insulina regular.

No Quadro 2 pode-se observar os medicamentos alguns medicamentos utilizados como tratamento para covid-19, além de informações de quando devem serem indicadas.

Quadro 2. Medicamentos propostos, suas indicações e tipo de uso segundo informações do bulário eletrônico.

\begin{tabular}{|c|c|}
\hline Medicamento & Indicação \\
\hline Heparina & $\begin{array}{c}\text { Profilaxiae tratamento de distúrbios tromboembólicos; prevenção da coagulação em cirurgia } \\
\text { arterial e cardíaca; como anticoagulante para transfusões de sangue, circulação extracorpórea e } \\
\text { procedimentos de diálise. }\end{array}$ \\
\hline Omeprazol & $\begin{array}{l}\text { Úlcera péptica gástrica, ou duodenal; esofagite de refluxo; síndrome de Zollinger-Ellison; } \\
\text { profilaxia de aspiração de conteúdo gástrico durante a anestesia geral em pacientes de risco. } \\
\text { Proteçãodo trato gastrointestinal superiorem pacientes seriamente doentes. }\end{array}$ \\
\hline Hidroxicloroquina & Lúpus Eritematoso, malária, artrite reumatoide. \\
\hline Ceftriaxona & $\begin{array}{l}\text { Infecções pormicrorganismos sensíveis a ceftriaxonaem locais de penetração adequada dela. } \\
\text { Profilaxia perioperatória de infecções. }\end{array}$ \\
\hline Azitromicina & Infecções por microrganismos sensíveis a azitromicinaem locais de penetração adequada dela. \\
\hline Oseltamivir & Profilaxia ou tratamento de influenza (A ou B). \\
\hline Ivermectina & $\begin{array}{c}\text { Infecções por Strongyloides stercoralis, Onchocerca volvulus, Wuchereria bancrofti, Ascaris } \\
\text { lumbricoides, Sarcoptes scabiei, Pediculus humanus capitis. }\end{array}$ \\
\hline Metilprednisolona & $\begin{array}{c}\text { Disturbios endócrinos, hematologicose reumáticos; Doenças do colágeno, do complexo } \\
\text { imunológico,dermatológicas,oftálmicas, gastrintestinais, respiratórias,neoplásicas, estados } \\
\text { alérgicosentre outros. }\end{array}$ \\
\hline
\end{tabular}

Fonte: Adaptado de (Braúna et al, 2021).

Machado et al. (2021), relataram que os estudos clínicos que analisaram o tratamento com corticosteroides, os de terapias alternativas utilizando exossomos e hemoperfusão, os com a droga Tocilizumabe e os com hidroxicloroquina e azitromicina mostraram que, os valores de saturação de oxigênio no sangue demonstraram uma melhora e houve dispensabilidade de ventilação mecânica, além disso, observou-se que esses prognósticos foram encontrados juntamente com a diminuição de marcadores inflamatórios, como a IL-6. Contudo, sempre é importante notar que em pacientes graves que fizeram uso de 
corticosteroides tiveram maior taxa de mortalidade e o Tocilizumabe foi associado a alto risco de infecções graves.

De acordo com Zuil et al. (2021), o efeito da combinação lopinavir/ritonavir (200mg/50mg duas vezes ao dia) por 8 diasauxiliouna nota-se uma redução da carga viral, observando-se a RT-PCR negativo no oitavo dia de tratamento. Mesmo que não tenha comprovação dos efeitos benéficos conclusivos da medicação, pelas limitações do estudo, pode-se observar que a combinação de lopinavir/ritonavir, inibiu a protease, enzima necessária para replicação viral, impedindo a conclusão do ciclo e, posteriormente, diminuindo a quantidade de vírus no organismo.

Além disso, o uso da medicina tradicional chinesa também foi discutido e analisada em estudo, onde foi utilizada a fórmula QPD e a fórmula LH, a partir disso observou-se efeitos antitérmicos e antivirais em ambas, com maior relevância na LH, melhorando os sintomas da SARS-CoV-2. A LH destacou-se no estudo como reguladora imunológica, por sintetizar a interleucina6 (IL-6) e melhorar o panorama de pacientes considerados graves. Essas terapias, fazem parte das diretrizes chinesas de tratamento para covid-19 (Zuil et al., 2021).

Alguns pacientes apresentam para quadros mais graves e estes necessitam de tratamento no hospital, que buscam garantir o controle dos dados vitais, já que não há, no momento, medicação disponível com efeito específico contra o SARS-CoV-2. Esse tipo de paciente normalmente carecem de oxigenação. Fontes de oxigênio de alto fluxo e ventilação não-invasiva têm sido utilizadas com base em experiências passadas com epidemias de gripes, mas ainda não foram avaliadas na epidemia atual. Note que estas abordagens geram aerossóis e requerem isolamento (Vieira et al., 2020).

\section{Conclusão}

Até o momento, sabe-se que parte dos casos de covid-19 desenvolvem sintomas leves (febre, tosse, dispneia, mialgia ou artralgia, odinofagia, fadiga, diarreia e dor de cabeça), outra parcela têm sintomas moderados (pneumonia), além de desenvolvem manifestações clínicas graves (pneumonia grave) que exigem oxigenoterapia, e uma menor porcentagem desenvolvem um quadro clínico crítico apresentando uma ou mais das seguintes complicações: insuficiência respiratória, síndrome do desconforto respiratório agudo (SDRA), sepse e choque séptico, tromboembolismo e distúrbios de coagulação e/ou insuficiência de múltiplos órgãos, incluindo insuficiência renal aguda, insuficiência hepática, insuficiência cardíaca, choque cardiogênico, miocardite, ou acidente cerebrovascular, entre outros.

O diagnóstico da pneumonia por covid-19 é possível através de PCR-TR positivo ou presença de alta suspeição clínica (clínica compatível + epidemiologia favorável) associada à TC com padrão em vidro fosco periférico bilateral de lobos inferiores.

Deve-se realizar medidas epidemiológicas de gestão de controle de infecções. Em paciente com prognóstico de casos leves devem ser tratados ambulatorialmente, a partir disso é recomendado o isolamento doméstico com a utilização de métodos de higiene, o deve ficar em isolamento dentro do quarto de porta fechada e bem ventilado, além disso deve-se realizar o uso de água e sabão ou álcool $70^{\circ}$ pelo próprio infectado, agitação e manuseio mínimos de roupas, higiene frequente de mãos de contactantes e do paciente, quarentena dos contactantes domésticos por 15 dias. Em caso de complicação do quadro do paciente sempre é recomendado orientar retorno e a ofertar afastamento laboral de contactantes domésticos por 14 dias.

\section{Referências}

Araujo-Filho, J. D. A. B., Sawamura, M. V. Y., Costa, A. N., Cerri, G. G., \& Nomura, C. H. (2020). Pneumonia por COVID-19: qual o papel da imagem no diagnóstico?. Jornal Brasileiro de Pneumologia, 46(2).

Braúna, C.C., Araujo, P. M., Carvalho, R. D., de Medeiros, M. D. G. F., \& Nunes, L. C. C. (2021). Farmacoeconomia aplicada ao tratamento medicamentoso para a COVID-19 em um hospital campanha. Revista Eletrônica Acervo Saúde, 13(2), e5971-e5971.

Costa, R. E. A. R., Cardoso, A. C., Martins, S. A. S., Amaral, S. M., Campos, L. N. R., Martins, L. R. G., ... \& Calaça, M. B. (2020). Complicações neurológicas em pacientes infectados por coronavírus. Research, Society and Development, 9(8), e242985687-e242985687. 
Research, Society and Development, v. 10, n. 5, e14710514600, 2021

(CC BY 4.0) | ISSN 2525-3409 | DOI: http://dx.doi.org/10.33448/rsd-v10i5.14600

Cui, S., Chen, S., Li, X., Liu, S., \& Wang, F. (2020). Prevalence of venous thromboembolism in patients with severe novel coronavirus pneumonia. Journal of Thrombosis and Haemostasis, 18(6), 1421-1424.

Ibrahim, AU, Ozsoz, M., Serte, S., Al-Turjman, F., \& Yakoi, PS (2021). Classificação da pneumonia usando aprendizado profundo a partir de imagens de raios-X de tórax durante o COVID-19. Cognitive Computation, 1-13.

Gattinoni, L., Chiumello, D. \& Rossi, S. COVID-19 pneumonia: ARDS or not ?. Crit Care 24, 154 (2020). https://doi.org/10.1186/s13054-020-02880-Z

Gil, A. C. (2017). Como elaborar projetos de pesquisa. São Paulo: Atlas. 6(4)175.

Machado, A. B. S., Alves, A. F., Araújo, H. R., Barros, J. F., Teixeira, L. S. F., \& de Moura, R. S. (2021). Terapias imunossupressoras no tratamento de COVID19: uma revisão integrativa da literatura. Brazilian Journal of Health Review, 4(1), 3656-3671.

Meirelles, G. D. S. P. (2020). COVID-19: uma breve atualização para radiologistas. Radiologia Brasileira, 53(5), $320-328$.

Mo, P., Xing, Y., Xiao, Y., Deng, L., Zhao, Q., Wang, H., \& Zhang, Y. (2020). Características clínicas da pneumonia COVID-19 refratária em Wuhan, China. Doenças Infecciosas Clínicas .

Peng, QY, Wang, XT, Zhang, LN e Grupo Chinês de Estudo de Ultrassom em Cuidados Críticos. (2020). Achados de ultrassonografia pulmonar de uma nova pneumonia por vírus corona durante a epidemia de 2019-2020. Medicina intensiva , 1.

Pereira, A. S., et al. (2018). Metodologia da pesquisa científica. [e-book]. Santa Maria. Ed. UAB/NTE/UFSM. Recuperado de https://repositorio.ufsm.br/bitstream/handle/1/15824/L ic_Computacao_Metodologia-Pesquisa-Cientifica.pdf?sequence=1

Ribeiro, G. E., \& Silva, D. P. C. D. (2021). Implicações audiológicas da COVID-19: revisão integrativa da literatura. Revista CEFAC, 23(1).

Soares, K. H. D., da Silva Oliveira, L., da Silva, R. K. F., de Assis Silva, D. C., do Nascimento Farias, A. C., Monteiro, E. M. L. M., \& Compagnon, M. C. (2021). Medidas de prevenção e controle da covid-19: revisão integrativa. Revista Eletrônica Acervo Saúde, 13 (2), e6071-e6071.

Tahamtan, A., \& Ardebili, A. (2020). RT-PCR em tempo real na detecção de COVID-19: problemas que afetam os resultados. Revisão de especialista em diagnóstico molecular, 20 (5), 453-454.

Vieira, S. C., da Silva Fontinele, D. R., Barjud, M. B., de Carvalho Junior, J. M., Melo, L. M. C., Fonseca Filho, J. W., ... \& Alencar, A. A. (2020). Tratamento precoce para COVID-19 baseado em evidência científica. Revista Brasileira em Promoção da Saúde, 33.

Yang, W., Sirajuddin, A., Zhang, X., Liu, G., Teng, Z., Zhao, S., \& Lu, M. (2020). O papel da imagem na nova pneumonia por coronavírus em 2019 (COVID19). Radiologia europeia, 1-9.

Xie, X., Zhong, Z., Zhao, W., Zheng, C., Wang, F., \& Liu, J. (2020). TC de tórax para pneumonia com doença coronavírus típica 2019 (COVID-19): relação com teste de RT-PCR negativo. Radiologia, 296 (2), E41-E45.

Zuil, D. M., Fontoura, V. M., Santos, F. S., Neto, M. S., Pascoal, L. M., Martins, M. C. N. S. E., ... \& Graepp-Fontoura, I. (2021). Esquemas terapêuticos para combate da Covid-19: revisão sistemática. Research, Society and Development, 10(1), e21310111533-e21310111533. 